\title{
AC 2007-2460: EXPERIENCES AND TEACHING TOOLS IN ALTERNATIVE ENERGY EDUCATION
}

\section{Slobodan Petrovic, Arizona State University}

Dr. Slobodan Petrovic is an associate professor at the Arizona State University, with teaching and research interests in the areas of alternative energy (fuel cells, hydrogen production and storage, $\mathrm{CO} 2$ reduction), MEMS and sensors. Prior to joining ASU Dr. Petrovic held appointments at Clear Edge Power (formerly Quantum Leap Technology) as a Vice President of Engineering; at Neah Power Systems as Director of Systems Integration; and Motorola, Inc. as a Fuel Cell Group Manager and Reliability Manager. Dr. Petrovic has over 20 years of experience in energy systems; fuel cells and batteries; industrial electrochemical processes; catalysis and sensors. He has 50 journal publications and conference proceedings; 2 book contributions, and 20 issued or submitted patents.

\section{Lakshmi Munukutla, Arizona State University}

John Robertson, Arizona State University 


\title{
Experiences and Teaching Tools in Alternative Energy Education
}

\begin{abstract}
Alternative Energy programs are emerging as a result of the growing need to develop the economy of the future that will rely not only on fossil fuels, but also on renewable and clean energy sources. The new generation of engineers that will support this shift in the energy production must develop truly multidisciplinary skills and be able to respond efficiently to various aspects of the alternative energy technology. "Fuel Cells for Portable Electronics" is a new course thought as a part of the alternative energy curriculum. The initial experience in teaching this course is presented in this paper. It underscores potential challenges because of the fact that engineering students join the graduate program in alternative energy from a variety of engineering backgrounds and with inconsistent knowledge of basic chemistry. The paper reports differences in student abilities to understand the fundamental electrochemistry concepts absolutely crucial for the subsequent introduction of more complex and practical fuel cell design and evaluation methods. A cursory comparison of test results revealed clear dependence on the student demographics. A qualitative conclusion was drawn recommending proper monitoring, exchange of experiences, and possible modification of prerequisites. Furthermore, a simple mnemonic tool was presented as an effective method to teach electrochemistry to engineering students.
\end{abstract}

\section{Introduction}

The main objective of this paper is to bring awareness about challenges when teaching energy related courses, such as those dealing with fuel cells, to engineering students of variable prior exposure to chemistry. Furthermore, the paper contains a discussion of the novel and entertaining methods for overcoming the lack of fundamental knowledge of electrochemistry for those students with little or rudimentary understanding of electrochemical principles while not sacrificing the ultimate outcomes of course, which are to provide practical, industry ready skills. These methods introduce equally challenging concept of designing an engineering course with ultimate integral quality expressed through a complete, interconnected understanding of the overall main objectives rather than fragmented knowledge acceptance typical for students with not well defined foundations. The paper also reflects the experience from working with limited student population and can only claim qualitative importance and informative character. As the alternative energy education becomes more important and a "main-stream" concentration for many institutions the observations and methods presented here could stand to gain validity and pave the way for a more "awakened" approach to teaching the alternative energy.

\section{Institutional Background}

The particular research data on the curriculum flexibility in engineering education was acquired at the Arizona State University at the Polytechnic campus. The Polytechnic was established in 1996 and the student enrolment grew from 1,016 in 1996 to 6,545 in 2006. The number of degrees offered is 30 baccalaureate and 12 graduate degrees. The mission of the College of Technology and Applied Sciences is to offer high-quality, problem oriented, learn-by-doing 
engineering, engineering technology and technology management. Department of Electronic Systems, which is one of the 7 departments within the college, offers a masters degree in Alternative Energy in one of its concentrations.

The Electronic Systems department at ASU's Polytechnic campus prepares all of its graduates through an industry-relevant master's degree curriculum ${ }^{1}$. The programs are driven largely by undergraduates who are employed in the industry and are always expected to provide students with knowledge and skills that enable them to get industry-relevant experience. The student body is composed from two groups: continuing students and international students.

Besides developing disciplinary knowledge and skills in their area of specialization as well as general studies competencies, students in all disciplines at the Polytechnic campus are expected to demonstrate knowledge and skills in the 7 core areas: ethics, communication, critical thinking, social and leadership skills, information literacy, scientific and technological knowledge and skills, and quantitative knowledge and skills. In their portfolios students must provide evidence that the learning has occurred in their majors and in the seven core areas. Furthermore, the strongest practical concept used at the Polytechnic is problem-based learning. The following main principles are expected to be incorporated and maintained in each class: students must have the responsibility for their own learning, the problem simulations must be ill-structured and allow for free inquiry, learning should be integrated from wide range of disciplines and subjects, the student self-directed learning must be applied back to the problems with re-analysis ${ }^{1}$. It will be described in this paper how the requirement to follow these principles created major issues in the newly established alternative energy course.

\section{Alternative Energy Program}

Energy supply for the future is the biggest challenge facing the current generation of engineers and scientists. There is very little disagreement left between once opposing sides in the debate on global warming and potential future energy crisis of catastrophic proportions. On one side, the world population is expected to reach $10 \mathrm{~B}$ by the year $2050^{2}$. Along with the consistently increasing demand per capita this is bound to require by the same year (i.e., 2050), at least 100\% increase in the installed power from currently $13 \mathrm{TW}^{3}$. At the same time, the reserves of conventional energy sources such as oil will not only be insufficient to meet this demand, but are expected to reach maximum exploitation rate 10 to 20 years from now followed by a rapid depletion and complete disappearance.

The reliance on fossil fuels has now been challenged by the collective consciousness around the world. Not only that the fossil fuel dependency puts future generations in jeopardy if energy sources get depleted, it also threatens the survival of the planet because of the negative effects on the environment primarily through global warming effects. It is clear that the energy demand for the future will not be met by presently used conventional energy sources and that the further increase in carbon dioxide levels will have disastrous consequences on the environment. The alternative is to provide enough energy to meet the demand decades from now and to protect the environment through the use alternative energy sources such as solar, wind, ocean, geothermal, and biomass. In a long run, the sustainable or renewable energy sources will be a viable option. This is supported by the fact that the global market for renewable energy is already dramatically 
increasing. In 2006 its turnover was US \$38 B, 26\% more than in the previous year and this trend is expected to continue ${ }^{3}$.

A dual energy crisis strategy of conservation or maximizing efficiency and vigorous development of alternative energy sources is proposed. The role of the Arizona State University as a New American University in this regard is the one of a bold leadership and relentless pursuit to promote and establish new energy sources.

The mandate of the newly established Alternative Energy program at Arizona State University at the Polytechnic campus is to strategically develop electronics engineering cadre capable of meeting the demands of the new energy economy that will rely on energy source different from traditionally exploited fossil fuels. When fully in place the program will offer education at the Associate of Applied Science degree (AAS), certificate program and the Bachelor of Science (BS), and Master of Science (MS) degree levels. The program currently comprises a large percentage of underserved minorities and will further assist and nurture these groups by preparing them for careers in high technology industries. The program will also serve to showcase industry-relevant education and training, to emulate a true industrial atmosphere, to promote public awareness for the renewable energy, and to provide community college and highschool teachers with development tools and other educational materials for early implementation in their classrooms.

All these facts have direct relevance to the main focus of this paper and have been considered during the fuel cell course evaluation and novel teaching method implementation phases.

\section{Fuel Cells for Portable Electronics}

The alternative energy program comprises courses covering wide range of topics. In the heart of the teaching strategy is the concept of the solar-hydrogen cycle. One critical link in that concept is development of fuel cells, which are considered the most efficient devices for converting chemical energy of the fuel to electricity. While stationary and automotive fuel cells have received a lot of attention, micro fuel cells for portable electronics have only entered a period of intensive research and development. However, it is broadly accepted that small, portable fuel cells have the best opportunity for commercialization. The reason for this is in the nature of the application and the incumbent technology limitations. Fuel cells are different from batteries based on the capacity for uninterrupted operation as long as the fuel is supplied. As a reminder, batteries contain active mass and after this active mass has reacted giving electricity battery is disposed (primary battery) or re-charged (secondary or rechargeable battery). From the point of view of microelectronic or nanoelectronic devices, fuel cells promise greatly better opportunities. Batteries in fact can be considered limiting factors in the progress of integrated micro and nanosystems. If a power supply is adjacent to nano-system for example and contained in the same package, then the necessity to change or recharge the battery can constitute a serious impediment for the whole device. Fuel cells have the advantage over all known types of batteries in terms of the energy storage capacity of fuel. In other words, the fuels used in fuel cells (typically methanol) contain much higher energy per unit volume and can therefore enable longer times of operation. 
The objective of this paper is to evaluate teaching methods used in this new, graduate level course offered for the first time in fall of 2005 as a special topic course and included in 2006 in the Alternative Energy curriculum. The main focus of this course is to give students practical knowledge of the fuel cell technology with specialization in micro fuel cells for portable applications. Significant emphasis is placed on the use of semiconductor materials and microfabrication techniques as a replacement for traditional fuel cell materials and processes. Another fact that separates this course from general fuel cell courses offered elsewhere is in the emphasis on microelectronics connection based on the need to train electronic systems engineers for immediate entry into industry.

The course curriculum was initially structured to provide only a brief background on the fundamental electrochemistry principles and to quickly move on discuss system components and their integration. However, in both years since the course has been offered the students unanimously expressed desire to master the basic understanding of chemistry and electrochemistry before proceeding to more specialized topics. It was the technical and scientific curiosity that has driven them to shift from their traditional thinking patterns and seek deeper basic science knowledge. While this presented a pleasant surprise and the class enthusiasm was welcome, the students generally lacked prerequisite knowledge of chemistry to successfully understand typically more complex principles behind electrochemical reactions. The subsequent analysis has demonstrated that ability to comprehend the electrochemistry principles outlined below depends critically on the science classes that students have taken as part of their undergraduate degree general competency requirements.

\section{Findings and Discussion}

One of the main objectives of this paper is to share the experience pertaining to a way basic chemistry knowledge should be thought to engineering students. It is apparent that student background plays a significant role in their capacity to comprehend simple concepts such as halfcell reactions, determination of the number of electrons in the reaction, and balancing chemical equations for redox reactions.

The course Fuel Cells for Portable Electronics is structured in three basic learning blocks or modules. The first module covers the following main topics: general introduction to electrochemistry, electrode potentials and measurement, standard reduction potentials, electromotive force, Gibbs Free Energy change and thermodynamics, Nernst equation and effect of concentration, Faraday Law of Electrolysis and fuel cell reactant consumption calculations based on the electrochemical kinetics. The experimental portion within this module includes laboratory demonstrations of the electrode potential measurements and electrolysis. The second module gives an in-depth perspective on the fuel cell historical development, fuel cell types, fuels for fuel cells, efficiency and voltage losses, fuel cell components and materials, and practical fuel cell preparation with the focus on direct methanol fuel cells. During this module students have the opportunity to prepare their own fuel cells membrane-electrode assemblies. The third module is especially tailored for the electronics engineering students with chapters in fuel cell electronics and power conditioning, DC-DC conversion, microcontrollers and programming, electrical motors, pumps and valves, process control tools, product life cycle, packaging and reliability, and special topics suitable for microelectronic students such as silicon- 
based fuel cells. In addition and in-line with the main mandate of the college, the final module combines students' technical and business skills with the developed sense of global awareness; and requires practical demonstration of the acquired knowledge through technical and business writing.

As evident from the description of the first module, the review of the fundamental electrochemistry is essentially matching the college chemistry courses. When the course was prepared for the fist time no problems were anticipated under the assumption that all the students have mastered these topics and a brief overview would bring them rapidly to a level of understanding necessary to successfully follow the rest of the course. Unexpectedly, roughly $40 \%$ of all students within the limited population evaluated have experienced difficulties integrating their chemistry knowledge and applying their skills to solve relatively simple problems involving balancing chemical equations and determining number of electrons involved in redox reaction.

The challenge at that point was to move through the course schedule as planned and at the same time give these students with difficulties an opportunity to master this critical skill, which is absolutely necessary for one of the practical computations involving the consumption of reactants in the fuel cell reaction. The fuel and oxidant consumption calculation in fuel cells was one of the essential skills required for passing the course. The formulas for fuel and oxidant consumption derived from the basic Faraday Law contain the number of electrons involved in the reaction. Without very proficient mastery of balancing equations for chemical reactions, recognizing half-cell reactions, and confidently deriving the number of electrons in the reaction students are at real disadvantage in learning subsequent essential skills such as complete modeling of the fuel cell performance in terms of fuel and oxidant consumption, fuel cell efficiency, and performance evaluation.

Furthermore, one of the core principles of education at the Polytechnic, the ill-structured problem simulation to allow for free inquiry, could not have been implemented at all due to this lack of basic understanding within the large percentage of students. It was also apparent for the course in whole that another key goal for the knowledge to be integrated from a wide range of disciplines and subjects diminished as a result of the problem student population. Fuel cells are very multi-disciplinary subject and would have under typical circumstances offered an ideal topic to integrate learning from chemistry, math, materials, and engineering. The deficiency in chemistry had in this case caused a problem and prevented a certain group of students from fully embracing the principle of multi-disciplinary integration. This was evident in testing as well as in class discussion and in homework. At this point, it was observed based on the same criteria, that the students were divided into two groups according to their ability to understand the simple concept of number of electrons in a redox reaction. This division matched nearly perfectly the demographic profile of the student body, i.e., there was a direct correlation between the success in the class and the origin of the undergraduate degree. Since Electronic Systems department of the College of Technology and Applied Sciences traditionally serves large percentage of foreign students in its graduate programs it is natural to place observation on the fact that students from foreign countries have demonstrated better overall aptitude for chemistry and have performed on average better in the class. While not knowing entirely the educational system in these countries it is evident that more solid background in chemistry and specifically in electrochemistry is 
produced. Students who obtained their undergraduate engineering degrees in India, Russia and China had very little or no problems with the concept and were eager to move faster and be exposed sooner to more complex topics in fuel cells. In contrast, the students educated in the USA had profound difficulties and were those who suffered from the lack of the basic chemistry understanding.

It must be stated very clearly that this conclusion in no way implies poor chemistry and electrochemistry background for all US educated engineering graduates. Furthermore, the segment of the chemistry graduates evaluated here is clearly only the electronics engineering student group and not any other major orientation. While all students have the same prerequisites for enrollment in Electronic Systems Department of 12 science credits, it is left up to students to decide between physics, chemistry, or biology. Those students who had only 3 or 4 credits in chemistry clearly had more difficulty learning this material.

This finding is based on the small student population and any further general implications would have to be verified through larger studies. However, the above mentioned division was salient and it appeared worthwhile reporting this anomaly. As a result, the conclusion from this paper should be read only as a call for attention or a warning of a potential problem that there may be lack of basic chemistry knowledge for electronic engineering students who obtain their undergraduate degrees in the US. As we enter the age of clean and renewable energy the profiles of graduates who will be trained in this area will change and the accompanying structuring of the undergraduate degrees may need to be revised to include more solid background in chemistry as it is crucially important for many alternative energy systems.

\section{Mnemonic device}

After the initial difficulties have been encountered in regards to student ability to understand fundamental electrochemistry, a novel approach was applied. It was based on a simple mnemonic principle, which will be demonstrated as an example. This was rather counterintuitive when having in mind that these were all fairly mature students, who at first felt that this simple memorization method was not an adequate way to stimulate their learning. However, after a first few attempts the students completely embraced the concept. The mnemonic tool was used to help students memorize the steps involved in balancing redox reaction equations. A "nonphrase" was developed: MOHiCan $\mathrm{H}_{2} \mathrm{OPE}$, with significant letters being capitalized. This translates into: balance elements (i.e., metals) other than hydrogen and oxygen, balance oxygen by adding water, balance hydrogen by adding protons, and balance charge by adding electrons.

After the initial success of this simple tool, a mnemonic technique was further used to help students memorize and maintain the integral picture of the fuel cell science and technology. To represent the 10 main topics that the course covers a 10-digit phone number was used. For example, the main topics are: Basic Electrochemistry, Entomology, Thermodynamics, Kinetics, Experimental Methods, History, Main Fuel Cell Types, Fueling Fuel Cells, Direct Methanol Fuel Cells, and Overview. Within each of the main 10 topics the numbers signify essential sub-topics. For example, the mnemonic number is: (602) 776-6457. By memorizing this fictional phone number the students retain nearly permanently the reminder that there are 6 sub-topics (i.e., questions) in the first topic of Basic Electrochemistry, or that there are 6 critical things to 
remember about the History of fuel cells. Please note that Entomology was assigned number zero meaning that there are no topics to remember about Entomology that are relevant to fuel cells. In parallel, the first letters of the topic name are grouped in "non-word" formation and serve as reminders of the topic. For example, the "non-word" is: BET KEHM FMO. From this, if a student knows that, for example, the fourth digit in the phone number is 7 and the fourth letter in a "non-word" is K, this would remind him/her that there are 7 important topics to remember from electrochemical Kinetics. It is evident that there is no direct connection with the actual questions, but this method has nonetheless produced excellent test results in integrating the knowledge into a solid structure without a danger of an important issue being overlooked. The students in both years initially resisted the mnemonic form of learning, but embraced it without reservation and with significant enthusiasm after a few weeks. A qualitative comparison was actually performed in those first few weeks between the students who adopted the mnemonic technique early and those who were initially resistant to this method of learning. It was very clear that the group using mnemonic test was showing more rapid progression towards understanding the material than the control group who did not use the technique.

The incorporation of the mnemonic exercise also introduced a less reserved atmosphere in the classroom and prompted spontaneous inter-student challenge. The partial poll of students 3 months after the class finished confirmed $100 \%$ retention of the mnemonic phone number and associated areas of fuel cells. A test was created based on this mnemonic device and was dubbed "Essential Knowledge Test". This has helped the students solidify their learning structure by providing way to remember a list of "must know" questions. Using the analogy of the learning pyramid the Essential Knowledge resides in the very top of the pyramid. The application of this teaching method has produced much improved test results of more than $20 \%$ in some cases and has generally helped in producing satisfied, empowered young experts in the field of fuel cells.

\section{Conclusions and Recommendations}

The paper has presented the findings on the potential issues that instructors in the field of alternative energy can face. It raises concern about the readiness of engineering graduates to enter and successfully complete graduate level alternative energy courses. The evaluation of the success in the scrutinized course and a very particular topic of redox reactions has shown that the lack of systematic knowledge of chemistry can impede and critically affect student progress in alternative energy courses such as fuel cells. Furthermore, it was established based on the limited student population that the certain groups of foreign students exhibit superior understanding of the basic electrochemistry principles compared to US educated students. While this conclusion is not meant to sound alarming because of the small student population discussed in this work, it is meant to raise the level of alertness towards this particular issue. If it turns out that the problem is wide-spread and persistent it might be necessary to revise the prerequisites for students entering alternative energy programs to include additional chemistry credits and to secure the overall success of the programs.

Another alternative would be to provide a summer or inter-session refresher course for those students that have not taken the necessary chemistry courses. In addition, a restructuring of the first module to more basic approach while extending the last module designed for electronics students could be considered. 


\section{References}

1. Lakshmi Munukutla, Albert McHenry, Robert Darveaux, and Govindasamy Tamizhmani, "Graduate Education with Industry Relevance”, Journal of Engineering Technology, Vol. 22, number 2, p 34-9, Fall 2005.

2. United Nations, "Long-range world population projections" - based on the 1998 revision; Energy Projections: "Global energy perspectives" ITASA/WEC

3. European Renewable Energy Council (EREC), "Energy Revolution: A Sustainable World Energy Outlook", January 2007. 